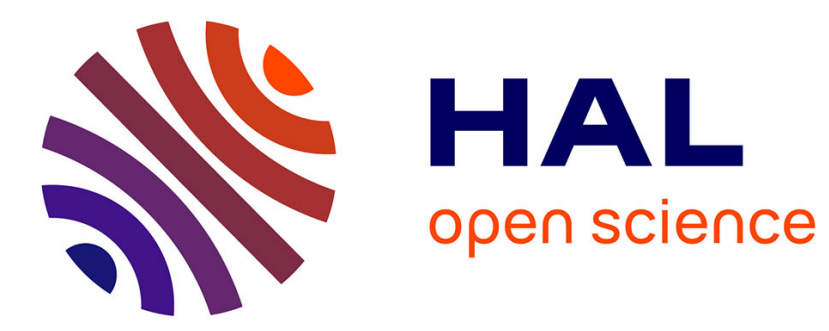

\title{
Spatial Aspects of Personification in International News
}

Marta Severo, Laurent Beauguitte

\section{To cite this version:}

Marta Severo, Laurent Beauguitte. Spatial Aspects of Personification in International News. Compagno D. Quantitative Semiotic Analysis, Springer, pp.171-189, 2018, Quantitative Semiotic Analysis. Lecture Notes in Morphogenesis, 10.1007/978-3-319-61593-6_9 . hal-03197841

\section{HAL Id: hal-03197841 https://hal.science/hal-03197841}

Submitted on 14 Apr 2021

HAL is a multi-disciplinary open access archive for the deposit and dissemination of scientific research documents, whether they are published or not. The documents may come from teaching and research institutions in France or abroad, or from public or private research centers.
L'archive ouverte pluridisciplinaire $\mathbf{H A L}$, est destinée au dépôt et à la diffusion de documents scientifiques de niveau recherche, publiés ou non, émanant des établissements d'enseignement et de recherche français ou étrangers, des laboratoires publics ou privés. 


\title{
Spatial Aspects of Personification in International News
}

\author{
Severo, Marta and Beauguitte, Laurent
}

2018

To cite : Severo M., Beauguitte L. (2018) Spatial Aspects of Personification in International News. In : Compagno D. (eds) Quantitative Semiotic Analysis. Lecture Notes in Morphogenesis. Springer, Cham.

https://doi.org/10.1007/978-3-319-61593-6_9.

\begin{abstract}
Together with politics, international news is often considered to be one of the most prestigious fields of journalism. However, making international news attractive is increasingly difficult. Today, one of the main strategies employed by journalists consists in mentioning individuals in the news. The reader is supposed to identify with the mentioned individual(s), and the story is expected to be more successful as a consequence. This paper investigates the interest of using quali-quantitative content analysis to study the semiotics of international news. We analyse six daily newspapers from three developed countries and examine three complementary aspects of the relation between individuals and international news : the level of personification, the type of individual mentioned and the geographical scale to which individuals is connected.
\end{abstract}

\section{Keywords}

Content Analysis - International News - Space $\cdot$ Personification $\cdot$ Rhetorical Strategies

\section{Introduction}

For a long time, international news was one of the most important elements for daily newspapers (Lévêque and Ruellan 2010 : 46-48). However, in light of the financial crisis, they face several challenges : while producing original news remains expensive (Hamilton and Jenner 2004), replicating this 
news on the Internet is cheaper. Several scholars have described the effects of digital technologies on journalism (Boczkowski 2005). One of the more worrying effects is related to concurrence. The issue of concurrence in the journalism sector is surely not new. The media mimesis -or 'the circular flow of information' to use Pierre Bourdieu's expression (1996)- has been demonstrated multiple times. A story published in one medium will without doubt be published easily by others.

The danger of losing a story is one of the main fears for a journalist. The Internet increases and speeds up this fear. News can circulate more quickly and be available on multiple supports without added costs. Moreover, the journalism scene is occupied by a new type of gatekeeper called 'cybermediaries' (Sarkar et al. 1995), which aggregate and spread information more quickly, mainly by relying on agency content. While this increase in information gatekeepers may initially be expected to produce major diversity of information, Marty et al. (2009) demonstrated through an empirical case study of French news websites that news published on sites is generally redundant and only few original stories can be identified. ${ }^{1}$

As a result, it is clear that the explosion of news on the web brings about the impoverishment of content. Diversity of information is just a mythical aspect, and generally content is unoriginal. Information must be diffused immediately. Consequently, the editorial work of the journalist is not as necessary for the diffusion of information online. An agency press release is often simply published and republished several times. And this is especially true for international news. Not only is this information very expensive for the newspaper, but the fact that other media can instantly reprise it can also make all efforts to satisfy the audience useless. As underlined by Chris Paterson (2005), 'as news providers increase in quantity and scope, the original sources of consequential international news stories are few' (145). He goes on to point out: 'I wish to suggest the problem identified here should be viewed as a manifestation of our globalised and converged age and not merely as a continuation of the news agency influence over international news which has existed for nearby a century and a half' (146).

Thus, the shift from print to web makes the situation of international news particularly complicated. Facing these conditions, international journalists look for new strategies to make their news more effective, that is to say, more appealing to readers without increasing costs. Indeed, an essential part of a journalist's job has always been to develop strategies to make news attractive and sellable to readers. In 1965, Einar Östgaard accurately studied these strategies and identified the main factors influencing the flow of news. Our hypothesis is that in present critical times the personification of inter-

1. Likewise, several scholars had comparable findings in other national contexts : Boczkowski and de Santos (2007) for Argentina, Dagiral and Parasie (2012) for Germany and Cottle and Ashton (1999) for the UK. 
national news has become one of the most widespread tactics. It consists in mentioning individuals in the news : the reader is supposed to identify with the individual(s) mentioned, and consequently stories are expected to be more successful. ${ }^{2}$ As an example, if literacy in Somalia is a non-saleable subject for a certain audience, the portrait of a student or an exemplary teacher in difficult conditions may be more likely to touch the public. Strategies used by journalists to personify news and consequently increase the reader's interest have changed in the last few years and have notably reached a higher degree of complexity. In particular, mentions of individuals in international news are not only more frequent, but are also built according to specific editorial choices, by varying the geographical scale and the type of individual mentioned.

Even if in the last fifty years, numerous scholars have reworked and empirically applied the intuitions of Östgaard, the personification strategy has rarely been explored and its interaction with spatial aspects has been studied even less. The aim of this paper is to provide semiotic analysis of these new editorial strategies based on personification. In particular, we argue that a quali-quantitative approach, based on content analysis, can be successful in exploring such a subject. In this paper, we examine and compare the international news of six daily newspapers from a perspective which involves mixing personification and geographical scale associated with individuals. By using quantitative content analysis, we will focus on which types of individual are mentioned and with which geographical scale they are associated. We will first briefly review the literature by focusing on the evolutions of the hypotheses of Östgaard in the work of succeeding scholars. Then, we will explain our corpus and our methodological choices. Finally, results will be presented by focusing on two aspects : the relation between the type of individuals mentioned and the type of newspaper; and the variation of personification based on geographical scale.

\section{International News, News Values and Personifi- cation}

Every day, millions of facts occur in the world and only a small portion of these become international news. The study of factors influencing the flow of news has interested numerous scholars in the last sixty years. Not only have many theoretical approaches been proposed to explain how a given fact

2. In this paper, we focus only on the strategies of personification employed by journalists without considering the corresponding practices of identification carried out by readers. It is important to note that no statistical data are provided about the use of newspapers' RSS feeds. The only way to study identification would be to carry out an empirical study with a sample of readers for each considered newspaper. This could an interesting subject for further research. 
becomes international news, but also several empirical studies have tried to test, validate and enrich these approaches. In this section, we briefly review the literature that has investigated the use of personification in international news theoretically and empirically. We first present the classical assumptions of two seminal articles from the 60s and then examine the debate that they have generated. This analysis of the state of the art will help us to identify research questions related to the personification of international news that have until now been barely investigated through a quantitative approach.

\subsection{The Foundations of News Value Research}

In 1965, two valuable papers for the development of news studies appeared in the same issue of a newly founded journal (Journal of Peace Research) : Einar Östgaard's 'Factors Influencing the Flow of News' and Johan Galtung and Marie Holmboe Ruge's 'The Structure of Foreign News. The Presentation of the Congo, Cuba and Cyprus Crises in Four Norwegian Newspapers'. Both papers have been cited hundreds of times over the decades and they remain frequently quoted today. Their approaches were quite different. Östgaard proposed elements of explanation for the international circulation of news (why is an event occurring in country $A$ related in country $B$ ?), while Galtung and Ruge investigated the value of facts in international news (when does fact become good enough to be mentioned abroad?). In other words, the first approach was mainly relational while the second was essentialist. Despite this general difference, both articles propose a similar explanation of the function of personification in news. ${ }^{3}$

According to Östgaard, news is basically a product which has to be sold in a given (and usually national) market : 'it will be taken for granted that the work of the agencies is primarily motivated by the wish to "sell" the news services to clients, and that major efforts are therefore made to "satisfy" these clients' $(1965,42)$. A way to improve the value of the news is to personify it (47). The process described is based on the reader psychology : 'the greater the possibilities of identification with the news, the greater will be the news flow', the identification being eased by 'cultural proximity and proximity in time', and, to a lesser extent 'proximity in a geographical sense' (46). Moreover, the author concludes that international news tends to 'exaggerate the importance of individual actions by big power leaders' (55) : a conclusion which is not empirically validated in the paper. As a matter of fact, Östgaard proposes a synthesis of literature without testing his assumptions.

Conversely, in their paper, Galtung and Ruge include both theoretical considerations and empirical validation -the latter being not always fully

3. Incidentally, they were not the first scholars to work on this topic. In 1949, Wilbur Schramm had already highlighted the importance of personification : "the case of selfidentification with the story is powerfully influential on the probability that a reader will select the story" $(1949,268)$. 
convincing (see below). Among the 12 factors influencing the international flow of news that the authors identify, two are related to the personification of news : reference to action of the elite ('F10 The more the event concerns elite people, the more probable that it will become a news item') and the reference to persons ('F11 The more the event can be seen in personal terms, as due to the action of specific individuals, the more probable that it will become a news item') (68, emphasis present in the original paper). In order to validate these two factors, Galtung and Ruge propose several hypotheses including : 'H1 : The more distant the nation, the higher the tendency to report elite action' (75), and 'H2 : The lower the rank of the person, the more negative the event' (77). The paper verifies both hypotheses [('common people are quoted in only 2 of the 612 cuttings from the Cyprus crisis' (77), 'common people have to appear or be presented in a negative context to make news' (78)]. It is worth noting that though both articles provided rich and strong theoretical frameworks for international news studies, they were fairly evasive regarding universality and validation of their assumptions. As a consequence, in the following years many authors have tried to complete the work of Galtung and Ruge by testing new methodological solutions to empirically verify the news factors or by proposing innovative factors that would influence news.

Without any claim of exhaustiveness, among the authors who worked on empirical validation, we can mention Karl Erik Rosengren who in 1970, recognized the difficulty of operationalizing personification and proposed to use sports news to test this hypothesis, 'since there are team sports and individual sports'. Similarly, one year later, Sande (1971) tried to verify the findings of Galtung and Ruge through a new methodological workflow, i.e. by combining content analysis with analysis of perception of media users. Regarding personification, the author underlined that persons must be considered not only as human beings but also in relation to their social role, but he did not test this empirically. More interestingly, he verified that personification is used more often in negative news. Then, other authors such as Peterson (1981) and Staab (1990) focused their attention on finding methodological solutions to verify the different treatment of the elite and ordinary people in news, but these articles do not provide decisive arguments either. Finally, there were scholars who favoured the option of identifying new news factors. For example, Harcup and O'Neill (2001) proposed to compare the 'power elite' -a factor already present in Östgaard paper- with 'celebrity' and 'entertainment' for distinguishing news that mentioned celebrities in the fields of sports or music.

In conclusion, we can note that even while studies of factors influencing the flow of international news have been the main focus of literature on news studies for more than 50 years, several research questions raised by Östgaard and Galtung and Ruge relating to personification are still open and yet to be subjected to empirical exploration and validation. 


\subsection{Some Under-Investigated Questions}

Based on this short literature review, we can identify at least three questions about personification in international news that require more attention and that could be interestingly investigated through semiotics assisted by quantitative tools.

First, these factors are often dealt with without considering their relation to the media source. In particular, is personification relevant to all types of media, and is it performed in the same way? Do a tabloid and a financial newspaper, for example, use this editorial strategy with the same frequency and modalities? According to previous studies, the level of personification should vary according to the type of audience targeted by the newspaper. For example, a reference newspaper would personify news less than a tabloid, and a financial newspaper would be more inclined to provide news regarding collective actors (enterprises), while a tabloid would privilege a celebrity. Taking this into consideration, our study aims to empirically verify whether and in what way the media source influences the strategy of personification. To do so, we have built a corpus consisting of different types of daily newspapers : reference, popular, thematic (financial) and tabloid.

Second, scholars have rarely provided empirical evidence about the types of individuals that are mentioned in international news. While many authors have underlined the distinction between the elite and ordinary people, empirical studies on this aspect remain rare -one of the main exceptions being Sophia Peterson's analysis (1981). Our paper is meant to fill this gap by quantitatively verifying the types of quoted individuals in the considered corpus. Notably, by considering the development of infotainment in the last decade (Brants 1998; Patterson 2000 ; Thussu 2007), we make the hypothesis that reference newspapers would mention mainly the elite of the (financial and political) ruling class, while tabloids would prefer ordinary people and celebrities. Based on this assumption, this paper aims to test empirically the kind of relation which exists between the type of newspaper and the type of individual mentioned in international news.

Last but not least, the spatial dimension has generally been overlooked in the small body of literature focusing of personification strategies. Many studies have tried to examine the geographical determinants of national (Bendix and Liebler 1999) or international news (Brooker-Gross 1983; Wu 2000), but the geographical scale of action associated with quoted individuals has rarely been considered. Considering this, the relations between types of individual and geographic scale of reference need further investigation, especially if we consider the rising interest in the spatial dimension of social phenomena in several disciplines. Our approach is related to the concept of socio-spatial abilities (Stoll 2005) : in contemporary society, geographical skills -the capacity to domesticate several scales from local to global- are unequally distributed among individuals, and their distribution tends to follow social and economic 
inequalities. Our study aims to verify if a particular type of individual is associated with a specific scale in international news. In doing so, we intend to test, for example, if ordinary people are mainly associated with a local scale, such as a city, while the elite may be connected to more global dimensions, such as a country or even a region.

\subsection{Personification in the News and the Model Reader of RSS Feeds}

This paper intends to study how personification is employed today in international news published on the Internet. In previous paragraphs, we have underlined the main thrust of this topic by considering both the limits of past studies and the current crisis of international news, which has made this strategy more popular than in the past. In order to study such a subject, we decided to perform analysis on the RSS feeds of the international section of a sample of newspapers' websites instead of on the full text of the articles.

RSS feeds are files (in XML) updated regularly by websites that give concise information about the publication of new content on a website. A feed consists of several items and each item is constructed according to standards (RSS 1.0, RSS 2.0 and Atom) and is characterized by mandatory fields (date, title, description, hyperlink). For newspapers, each item corresponds to a news item on the website and is normally composed of the headline, a short summary and the hyperlink to the article published on the website. The summary may be written by the journalist, or may match the beginning of the article. In our sample, Le Parisien gives the beginning of the article, the other newspapers provide a summary, which usually consists of just two or three lines of text which briefly present the main content of the news - the mean length of summary is 240 characters.

As we have previously demonstrated (Severo and Beauguitte 2015), RSS feeds can be an alternative source of information for media studies and, in our case, provide enough information to evaluate : if an individual is mentioned; the type of individual; and the geographical scale of the news. Moreover, RSS feeds provide some important advantages compared with a corpus of full-text articles to perform quantitative analysis : they are freely accessible, so they may be archived and tagged without limit; and they have a fairly homogenous structure, so they are easily comparable. In particular, this corpus has been extracted from the RSS database of the ANR Geomedia Project, ${ }^{4}$ which stores RSS feeds associated with articles published in one hundred newspapers in different parts of the World.

RSS feeds are also interesting because they allow us to examine the impact of the Internet on the job of the journalist. By analysing RSS feeds,

4. ANR Corpus GEOMEDIA (2013-2016) http://geomedia.hypotheses.org/ (accessed 14 November, 2016). 
this research sets out to study the phenomenon of the impoverishment of news content on the Web. RSS feeds play a basic role in summarizing news, attracting the reader with a few lines of text and inducing him/her to carry out a specific action, that of clicking the link to access the entire article. This action is clearly the result of a certain interpretation of the RSS feed. Therefore, our research is based on the hypothesis that journalists tend to create a specific model reader in their RSS feeds in order to encourage this reader to click on the link.

Eco (1979) defines the model reader as an interface for the reader, guiding his/her interpretation. The model reader, in essence, is 'a textually established set of felicity conditions [...] to be met in order to have a macro-speech act (such as a text is) fully actualized' (Eco 1979 : 11). Texts foresee their readers and guide their interpretation along a certain path. In particular, some texts -such as RSS feeds- have a practical interactive outcome : the action of clicking (Zinna 2004). Journalists must develop very basic yet effective strategies to obtain the click of the reader. So, our hypothesis is that personification is not only a rhetorical strategy often adopted by contemporary journalists to make their news more attractive, but that this is especially true for newspapers' RSS feeds. Personification is not just the choice of certain content over other content, as is the case of infotainment. It is rather a more abstract rhetorical strategy, influencing the way in which content is presented.

We assume the effect of personification to be linked to identification of the reader with the kinds of thematic roles (Greimas 1987) mentioned in the RSS item. Indeed, we can state that there are two reading contracts (Eco 1979) in RSS : one is visible and roughly states 'information has to be short' and one is hidden and is meant to obtain the decisive click. This hidden reading contract can be studied by analysing one of the rhetorical strategies related to it, i.e. personification.

\section{Methodology}

In the continuation of this paper, we aim to investigate the reading contract hidden in RSS feeds, and, in particular, its rhetorical strategypersonification. Based on the state of the art review, we identified three aspects related to the personification of international news that require further exploration : the impact of the media source (notably the type of newspaper) on personification; the link between the type of individual mentioned and the type of newspaper; and the link between the type of individual mentioned and the geographical scale of reference of the news in which s/he is mentioned. Semiotics aided by quantitative techniques has been identified as the most suitable framework to provide empirical evidence to investigate these three aspects. The methodological workflow has been organized as follows. 
First, we built the corpus of analysis. We selected six newspapers which were expected to show great variation along two axes. The first axis was the level of personification, that is to say the quantity and the variety of individuals mentioned, which can vary from the lowest level of personification corresponding to newspapers that rarely mention individuals in international news, to the highest level, for daily newspapers that not only always mention individuals in their stories but also pay attention to their variety. The second axis is the geographical scale of reference of news, which can vary from the local to the global scale.

We selected six daily newspapers from three developed countries. In each country, we chose a reference newspaper : Le Figaro in France, The Daily Telegraph in the UK and The Australian in Australia. Then, in the same countries we identified a second newspaper of a different type that has a different target audience : a tabloid in Australia (The Daily Telegraph in order to differentiate it from its English namesake, we have termed them The Daily Telegraph UK and The Daily Telegraph AUS afterwards); a popular newspaper (Le Parisien in France) and a thematic one (The Financial Times). We selected newspapers from democratic and wealthy countries as we presume that the role of the press is somewhat similar in these countries. In order to control possible geographical variations, we chose two neighbours (France and the United Kingdom) and a far-off country (Australia).

Secondly, we formulated three hypotheses, one for each facet of personification to be studied. Such hypotheses would help us not only to estimate the position of each newspaper considered along the two axes, but also to identify the feature that can be quantitatively measured in order to empirically verify such a hypothetical position.

As regards the first aspect, the impact of the media source on personification, we can formulate the following hypothesis : the more lowbrow the audience targeted, the higher the importance of the individual in news. According to this statement, the need for personification is supposed to be much higher for a popular or a tabloid newspaper than for a reference newspaper that targets a more sophisticated audience. It would therefore be interesting to verify empirically the amount of news mentioning individuals for each newspaper in the considered corpus.

As regards the second aspect, the type of quoted individuals, we formulated the following hypothesis : While reference newspapers focus on the elite, popular ones focus on ordinary people. According to this hypothesis, while we expect a high level of personification in most newspapers, we do not expect them to discuss the same type of individuals. This hypothesis tries to minimize the Östgaard and Galtung-Ruge assumptions regarding the prominence of the elite in international news. In order to empirically verify this, it will be necessary to classify and count individuals mentioned according a typology, and verify the distribution of individual's types according to type 
of newspaper.

Based on the experience of previous studies (Galtung and Ruge 1965; Herkenrath and Knoll 2011), we selected four types of individual : elite (responsible for finance/economy and politics); actor (agent); celebrity (entertainment); and victim (person affected by an event). These types of individual are different thematic roles, in semiotic terms (Greimas 1987). Indeed, personification pertains to the so-called discursive level, where the narrative structures are materialized by lexical figures. These figures do not all have the same level of abstraction : a sentence can avoid referring to a specific thematic role (she did it), whereas some semantic features may be made explicit (the girl did it).

In particular, proper names play a worthwhile role as encyclopaedic references, which link the discourse not only to a generic linguistic competence but to a specific knowledge of the world (Eco 1976, 2000). Each proper name is linked to a number of possible contexts in which it can be used, and its use brings with it the memory of these possible contexts of use. So, it is possible to extract the main connotations of these proper names, both according to the textual context in which they appear and more broadly to the discourse in which textual production is carried out. As a methodological consequence, we had to combine analysis based on statistics with a preliminary qualitative interpretation of the corpus.

Moreover, it must be underlined that the qualitative application of this typology is not at all simple. The distinction may seem tenuous : a movie star can represent an institution and be the victim of a tragic event. We considered the function and the vocabulary associated with the person to code litigious cases : a politician who was the victim of an attack was first considered a politician, and so was coded elite. A film star representing UNICEF was also coded elite as their appearance is related to this specific function. Another problem was related to the presence of two individuals in a news story (i.e. a murderer and their victim) : to account for this we decided to consider only the first person quoted in the item.

Finally, as regards the spatial dimension of personification, we expect that : A clear relation exists between the types of individual mentioned and the geographical scale of the news. In particular, while ordinary people are likely to appear in local news, the elite would be included across various scales. As regards geographical scale, we identified six modalities : local, national, international, regional, global, and none. A piece of news is considered local when its geographical scope is below national scale, such as a department/county, etc., a city or even a neighbourhood of a city; it is considered national when one unique country is concerned. The international modality refers to bilateral relations (a story involving two different countries), for example when officials from one country meet officials from another country. Finally, the regional modality refers to a supranational level of analysis 
(all the countries of a region are involved) : information regarding Europe, sub-Saharan Africa, etc.

Figure 3 represents the expected relative position of our six newspapers in relation to the level of personification (amount and variety of quoted individuals) and the geographical scale of reference of the news. We expected to find news with a high level of personification and with local scope in tabloid and popular newspapers such as The Daily Telegraph AUS and Le Parisien. Conversely, a thematic journal such as The Financial Times, which enjoys a global, highbrow audience, was expected to privilege international and global news and show a lower level of personification. Finally, in the three reference newspapers, we expected to find mostly international news with an average level of personification.

FIGURE 1 - Expected configuration regarding scales and personification

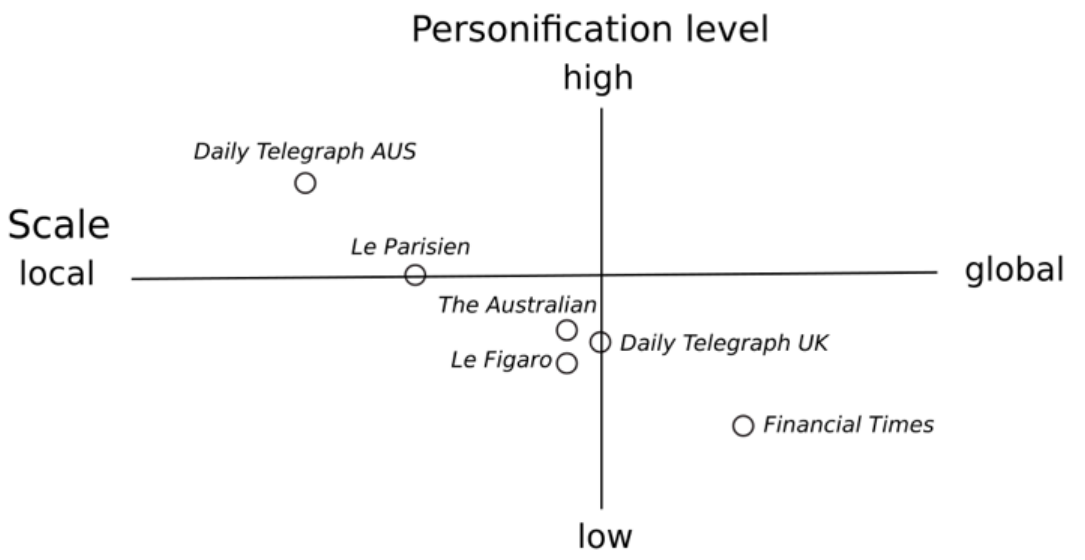

\section{Results}

Analysis was performed on the RSS feeds of the international section of the selected newspapers during a period of two and a half months (from December 15th 2013 to February 28th 2014). Following a classical workflow of quantitative content analysis, a set of coding rules was established, then the two authors coded each item separately according to the following criteria : presence of an individual $(1 / 0)$ and, when an individual is present, presence of a name (0/1), type of individual (four modalities) and geographical scale (six modalities). A codebook was tested on a first corpus, then the two authors tagged all items separately before comparing their results. The level of agreement was around $80 \%$, so $20 \%$ of items were coded after discussion between the authors. 


\section{Box 1 : Categorization of an RSS item}

The Australian, 29 December, 2013.

Title : "Black widow" bombs Russian station'.

Description : 'A FEMALE suicide bomber killed 16 people in a Russian train station, heightening security fears just six weeks before the Sochi Olympic Games'. The item is tagged local -a specific place in Russia, Sochi, and an actor is present -the 'black widow' being the agent of the news.

\subsection{1 Variations in Personification Based on Newspaper Type}

Before beginning validation of the hypotheses, two general remarks about the analysed corpus should be made (Table 1 summarizes the main features of the gathered corpus). First, the raw number of items regarding international news during the period presents significant variation between newspapers (ratio from 1 to 5 between Le Parisien and The Daily Telegraph UK), but these differences are less apparent on a national scale. Second, the tendency to personify news is significant in all newspapers. On average, more than half of news items mention individuals.

TABLE 1 - Levels of personification in the newspapers corpus

\begin{tabular}{lllll} 
Title & $\begin{array}{l}\text { Country } \\
\text { and type }\end{array}$ & $\begin{array}{l}\text { N. of } \\
\text { items }\end{array}$ & $\begin{array}{l}\text { Items with } \\
\text { individuals }\end{array}$ & $\begin{array}{l}\text { \% items with } \\
\text { individuals }\end{array}$ \\
\hline Le Parisien & FR popular & 643 & 402 & 62.5 \\
Le Figaro & FR reference & 607 & 380 & 62.6 \\
The Daily Telegraph & AUS tabloid & 1102 & 691 & 62.7 \\
The Australian & AUS reference & 1155 & 676 & 58.5 \\
The Financial Times & UK economic & 1089 & 478 & 43.9 \\
The Daily Telegraph & UK reference & 2585 & 1437 & 55.6
\end{tabular}

Source : Geomedia database, 2013-2014

As regards the impact of the media source, we can observe that The Financial Times is the only newspaper with a level of personification regarding international news below 50\%. This fact seems to confirm our first hypothesis concerning the impact of the media source on the level of personification. As expected, the financial newspaper is the one with the lowest level of personification as only $44 \%$ of all items concern an individual. Conversely, no clear hierarchy appears between reference and popular newspapers : in France, Le Figaro and Le Parisien get a similar level while in Australia, the reference newspaper The Australian presents a slightly lower level than the 
tabloid The Daily Telegraph. Whichever the audience targeted, it seems that mentioning individuals in news is a shared strategy amongst journalists.

As regards the link between the type of quoted individual and the type of newspaper, as already stated, we expected that the reference newspapers to focus more on the elite and the popular newspapers and the tabloids on ordinary people. Table 2 provides the percentage of individual type per newspaper. A $\chi^{2}$ test was carried out on raw numbers in order to validate these relative results. One main opposition appears regarding the interest in victims (which among the four categories is clearly the one that best represents ordinary people) : The Financial Times (less than $6 \%$ of items involving individuals) against the Australian tabloid (more than $46 \%$ of all items involving individuals). Less pronounced are the differences of interest in elites and actors. Results regarding celebrities are more difficult to interpret due to the small number of items involved. Indeed, the period considered saw only the death of film star Philip Seymour Hoffman, the skiing accident of racing driver Michael Schumacher and, less mentioned, a story involving the teen idol Justin Bieber. It seems that their presence is generally higher in English-language newspapers than in French ones, and, as expected, remains low in the Financial Times. This difference could possibly be explained by differences in the popularity of the celebrities concerned between the three countries. Nevertheless, further investigations into the tendency to mix hard news and infotainment (Patterson 2000) would be necessary to explain these results.

TABLE 2 - Types of individuals per newspaper (percentage)

$\begin{array}{lllll} & \text { \% Actor } & \text { \% Celebrity } & \text { \% Elite } & \text { \% Victim } \\ \text { Le Figaro } & 15.53 & 0 & 72.11 & 12.37 \\ \text { Le Parisien } & 14.43 & 0.75 & 67.16 & 17.66 \\ \text { The Daily Telegraph AUS } & 26.05 & 2.89 & 24.75 & 46.31 \\ \text { The Australian } & 22.86 & 7.91 & 50.59 & 18.64 \\ \text { The Financial Times } & 12.76 & 1.05 & 80.54 & 5.65 \\ \text { The Daily Telegraph UK } & 23.69 & 3.04 & 58.11 & 15.17\end{array}$

Two preliminary conclusions can be stated at this stage. First, and unsurprisingly, tabloid journalists often use the strategy of personification, by quoting several individuals, notably victims. Conversely, financial journalists are far less concerned with personification and even less with mentioning victims. Secondly, in some cases such as the French newspapers, the targeted audience does not seem to affect the level of personification of the newspaper. 


\subsection{Variations in Personification Based on Geographical Scale}

Before focusing on the third hypothesis by examining links between type of individual mentioned and geographical scale, it is useful to verify which scales journalists mainly mention. Table 3 provides, for each newspaper, the percentage of items mentioning individuals in relation to each considered geographical scale.

TABLE 3 - Scales of reference percentage of items per newspaper

$\begin{array}{lllllll} & \text { Local } & \text { National } & \begin{array}{l}\text { Inter- } \\ \text { national }\end{array} & \text { Regional } & \text { Global } & \text { None } \\ \text { Le Figaro } & 12.89 & 44.21 & 30.53 & 8.68 & 2.11 & 1.58 \\ \text { Le Parisien } & 18.16 & 33.58 & 35.82 & 4.98 & 4.48 & 2.99 \\ \text { The Daily Telegraph AUS } & 22.58 & 27.93 & 14.91 & 0.43 & 0.72 & 33.43 \\ \text { The Australian } & 20.12 & 43.20 & 23.22 & 2.51 & 2.07 & 8.58 \\ \text { The Financial Times } & 5.23 & 65.90 & 15.06 & 9.62 & 2.30 & 1.88 \\ \text { The Daily Telegraph UK } & 14.13 & 41.06 & 27.35 & 4.18 & 2.85 & 0\end{array}$

Individuals mentioned in international news can be connected to a large variety of geographical levels. You can find a local fact occurring abroad (a strike, a riot, etc.), a national news story that concerns a whole country (e.g. a presidential election), a story involving several states (meetings, conflicts) or global news such as climate change.

If we return to our expected configuration regarding levels of personification and geographical scales (Fig. 3), we note once again that our corpus does not follow this hypothetical model. Based on empirical results, a new model can be built (Fig. 4.2), in which several newspapers have a quite different position in relation to what was expected.

While the local scale is important for Le Parisien (popular newspaper), it is more frequent in The Daily Telegraph UK and in The Australian (reference newspapers). The interest in regional and global scales was expected to be higher for The Financial Times but this is not really the case. We can also see for all the newspapers considered, an international news story is mostly a local or a national fact occurring abroad. However, the most surprising result concerns the a-spatial level of items in the Australian tabloid : a third of all items involving individuals do not make any reference to a geographical level. We refer to items like the following :

A 14-YEAR-OLD girl was shot dead by her stepfather after he reportedly mistook her for a burglar. (24 December 2013).

Many facts reported in the RSS have this structure : a victim, always characterized by gender and age, and the circumstances of the victim's death, but with no first name or the location of the incident. Our interpretation is 
FIGURE 2 - Observed configuration regarding scales and personification

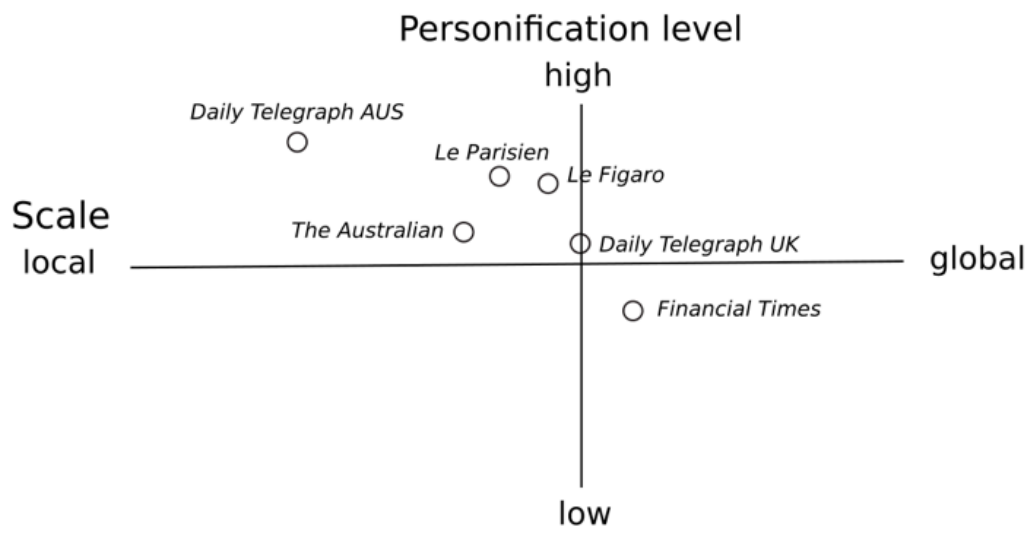

that this structure of news is made to maximize the level of personification : as first name or places are not indicated, it could have happened anywhere to anyone.

Another possible way to find regularities between the types of individual and the geographical scale is to analyse the variety of scales mentioned about the same type of individual. We can expect the elite to be more plural in their relations to space, and victims to be mainly associated with the local scale. From a methodological point of view, we should obtain positive $\chi^{2}$ residuals when a specific scale is often associated with a specific type of individual. Conversely, a negative residual would indicate a negative relation between these characteristics. As The Daily Telegraph AUS is very specific regarding scale, it was not considered for this part of the analysis -the high level of aspatial news would make the residuals impossible to interpret. Through this methodological solution we can validate hypothesis 3 : indeed, regarding victims, the local scale is predominant in our five newspapers.

The international scale is significantly positive only for The Australian and the reading of all items helps to understand why : two kinds of victims frequently appear in this newspaper, spectacular drama occurring in a specific place abroad, and relatively tragic incidents involving Australian citizens abroad. Conversely, the elite can be associated with different scales, generally at the national and the regional levels, more rarely at the local, except for The Financial Times (Table 4). 
TABLE $4-\chi^{2}$ residuals - the elite and victims

$\begin{array}{lllll}\text { ELITE } & \text { Local } & \text { National } & \text { International } & \text { Regional } \\ \text { Le Figaro } & -5.23 & 1.35 & 1.08 & 2.52 \\ \text { Le Parisien } & -4.69 & 2.77 & -0.16 & 2.23 \\ \text { The Australian } & -5.57 & 7.28 & -1.76 & 2.15 \\ \text { The Financial Times } & -0.56 & 1.93 & -1.56 & 1.58 \\ \text { The Daily Telegraph UK } & -8.27 & 5.94 & -1.59 & 1.54 \\ & & & & \\ \text { VICTIM } & \text { Local } & \text { National } & \text { International } & \text { Regional } \\ \text { Le Figaro } & 4.62 & -0.56 & -1.81 & -2.26 \\ \text { Le Parisien } & 3.43 & -2.45 & 0.97 & -1.52 \\ \text { The Australian } & 3.65 & -3.63 & 1.85 & 0.54 \\ \text { The Financial Times } & 2.30 & -0.33 & -0.04 & -1.07 \\ \text { The Daily Telegraph UK } & 6.01 & -4.43 & 0.82 & -0.85\end{array}$

\subsection{Some Individuals in Different Spaces}

Before testing the ability of the elite to appear on different scales, it must be remembered that the international news actors are highly concentrated : a small number of actors regularly appear while most of them only make a single appearance. Preliminary tests revealed that nearly $90 \%$ of all individuals appear just once in New York Times RSS flows for international news (Beauguitte and Severo 2014). This proportion is roughly the same for our six daily newspapers (percentage range from 82 to $92 \%$ ).

Considering those persons that appear several times, the first interesting result is that only a few names are common on our corpus : Barack Obama; the two popes (the period considered saw the resignation of Pope Benedict XVI and the election of Pope Francis); François Hollande (revelation of his affair with a French actress); Vladimir Putin and Viktor Yanukovych (Russian intervention in Ukraine); and Kim Jong-un are the main political actors mentioned during the period. Persistent individuals not related to politics are few. Philip Seymour Hoffman (drug-related death) and Michael Schumacher (serious skiing accident) are the only names of celebrities that appear in our corpus. Once again, the Australian tabloid stands out : there are very few persistent individuals (only four persons quoted ten times or more) and, accordingly, political leaders and celebrities are less mentioned than in the other newspapers. This fact can be considered as more evidence of the importance of personification for the journalists of this newspaper.

Moreover, when we consider the relation of individual space-time, a clear national bias appears in the two French newspapers as Hollande is in both cases the most mentioned public figure -conversely, British and Australian political leaders do not appear among the top-mentioned persons in British 
and Australian newspapers. Many studies have highlighted national bias in international news (Bendix and Liebler 1999; Chaudhary 2001; Herkenrath and Knoll 2011) but, being mainly based on a single newspaper, the universal validity of these criteria does not appear completely assumed. Tests made on a bigger corpus (38 newspapers from 18 different countries) by the authors revealed that national bias appears only in a limited number of cases and could be especially low in wealthy geographically peripheral countries, such as, for example, New Zealand (Beauguitte et al. 2016).

Finally, within this small corpus, it appears that only a couple of individuals are famous and prominent enough to appear on different scales in the international news : Barack Obama and the two popes are able to appear on the local, national, international and global scale (Fig. 4.3). Conversely, the others are mainly associated with one or two scales of reference (Fig. 4.3). We think that if a different period were examined, Barack Obama could be the only world leader quoted frequently on different scales -let us recall that the period under consideration saw the exceptional resignation of a pope and the election of a new one.

Figure 3 - Two global and pluri-scalar actors : Obama \& the Pope

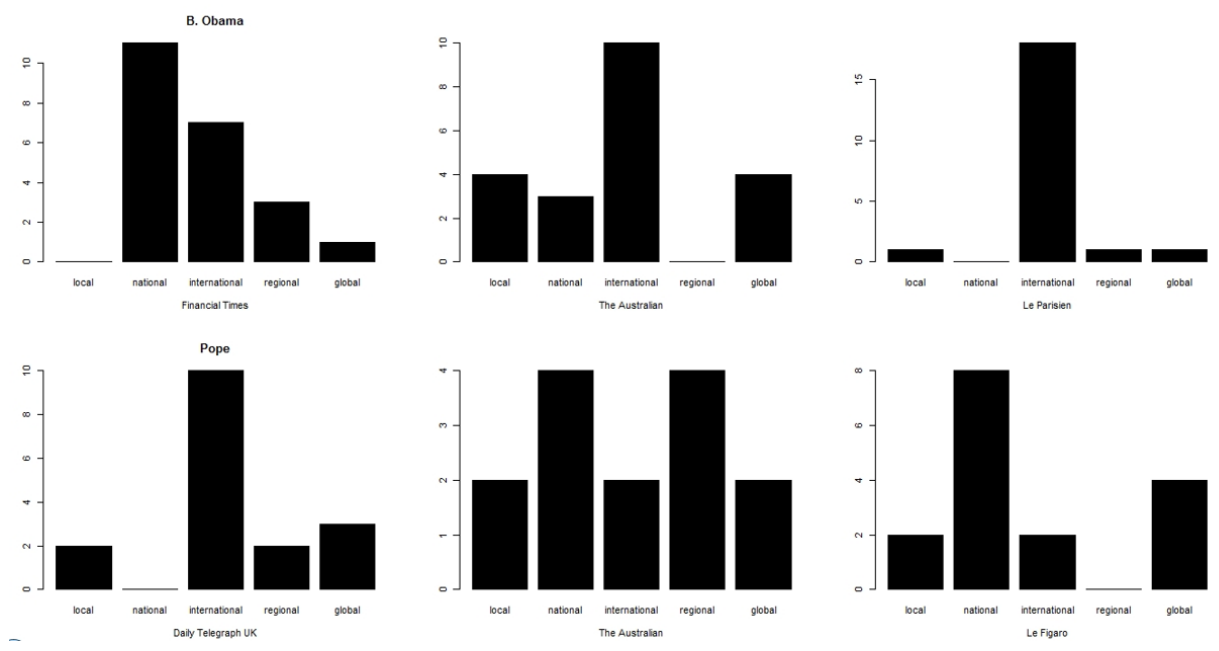

\section{Conclusion}

Personification is a common strategy used by journalists to make the news more interesting for the reader. It is also used to present international events that may involve collective actors (states, intergovernmental or nongovernmental organizations, firms and so on) rather than individual ones. This technique, studied for more than 50 years in news research, is still very 
FiguRE 4 - Hollande and scales of reference
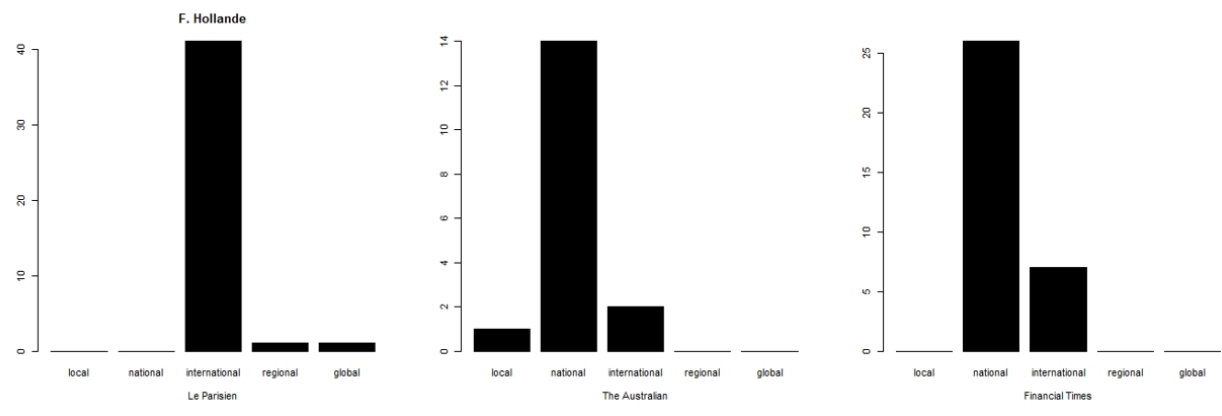

popular among journalists. However, the intensity and mode of personification depends on editorial choices. This paper provides empirical evidence of how the personification of international news is used as a rhetorical strategy in the hidden reading contract of RSS feeds to make the reader click on the link to the news. The journalist builds a model reader based on personification that may vary according to the type of newspaper, the type of individual mentioned and the spatial scale on which the individual is mentioned.

Journalists can choose to mention a type of individual rather than another or to mention the proper name or not, depending on the audience targeted by the newspaper. So, reference newspapers focus on major political leaders, while popular ones focus on anonymous victims. The presence of celebrities from the spheres of sport or entertainment remains marginal : reference newspapers do not include them in the international news section and popular newspapers only mention them when a scandal occurs. Regarding the spatial dimension, scales of reference vary greatly and are related to the unequal persistence of actors in international news. Most individuals appear once and are associated with a local scale of reference, but only a couple of world political leaders appear frequently and on a multi-scalar perspective. One of our most striking results is that the individuals suitable for frequent mention, often on several scales are very few, even with a small and culturally homogeneous corpus (wealthy countries sharing common values) : the Pope and Barack Obama.

Considered from a semiotic perspective, in this chapter personification has not been studied through the qualitative analysis of a restricted corpus but through the quantitative investigation of some relevant features and their further evaluation through quali-quantitative interpretation. Furthermore, discourse variables (such as the presence/absence of a proper name or the comparison of their connotations) are integrated with geographic metadata such as the location of the newspapers considered. This paper therefore 
investigates the correlations between discursive regularities and production practices.

This research is meant to propose an interdisciplinary approach combining quantitative content analysis with semiotics applied to the study of media discourse. We identified discursive regularities and attributed them to a hidden reading contract (aimed at producing the reader's click); we identified one main rhetoric strategy (personification) behind this implicit contract; we defined a structural way to study it (by differentiating some degree of personification on the basis of the connotations of proper names and other terms associated with thematic roles). Further work can benefit from greater semiotic insight; for example, by focussing on analysing discourse segments instead of isolated words, or by investigating the narrative role of proper names, beyond the simple observation of their presence/absence.

On the other hand, we think that semiotics can benefit from research traditions such as quantitative content analysis because (1) these studies have a semiotic interest even if they are carried out with methods that are not familiar to semioticians; (2) these methods seek empirical regularities often overlooked by traditional semiotics, going beyond mere immanent discourse analysis; and (3) they allow previously undervalued observation of qualitative aspects of signification -some new observables which cannot be studied solely by qualitative research (Rastier 2011).

\section{References}

Beauguitte, L. and M. Severo. 2014. Les flux RSS pour les études territoriales: une analyse de l'individu et ses espaces dans les actualités internationales du New York Times. In Proceedings du 2e colloque international du CIST 32-37.

Beauguitte, L., Severo, M. and H. Pecout. 2016. Une analyse géomédiatique de l'actualité internationale : hiérarchies et effets de voisinage. L'Espace géographique 45(2): 124-141.

Bendix, J. and C.M. Liebler. 1999. Place, Distance, and Environmental News : Geographic Variation in Newspaper Coverage of the Spotted Owl Conflict. Annals of the Association of American Geographers 89(4) :658-676.

Boczkowski, P.J. 205. Digitizing the News : Innovation in Online Newspapers. Cambridge, MA : MIT Press.

Boczkowski, P.J. and M. de Santos. 2007. When More Media Equals Less News : Patterns of Content Homogenization in Argentina's Leading Print and Online Newspapers. Political Communication 24(2) :167-180.

Bourdieu, Pierre. 1996. Sur la télévision suivi de L'emprise du journaliste. Paris : Liber, Raisons d'agir. 
Brants, K. 1998. Who's Afraid of Infotainment? European Journal of Communication 13(3) : 315-335.

Brooker-Gross, S.R. 1983. Spatial Aspects of Newsworthiness. Geografiska Annaler, Series B, Human Geography 65(1) :1-9.

Chaudhary, A.J. 2001. A Comparative Content Analytical Study of Negative News in Western and Third World Newspapers. Asian Journal of Communication 11(1) :25-50.

Cottle, S. and M. Ashton. 1999. From BBC Newsroom to BBC Newscentre : On Changing Technology and Journalist Practices. Convergence 5(3) :22-43.

Dagiral, E. and S. Parasie. 2012. Presse en ligne : où en est la recherche? Réseaux 2 :13-42.

Eco, U. 1976. A Theory of Semiotics. Bloomington : Indiana University Press.

Eco, U. 1979. The Role of the Reader. Bloomington : Indiana University Press.

Eco, U. 2000. Kant and the Platypus. Boston : Houghton Mifflin Harcourt.

Galtung, J. and M.H. Ruge. 1965. The Structure of Foreign News. The Presentation of the Congo, Cuba and Cyprus Crises in Four Norwegian Newspapers. Journal of Peace Research 2(1) :64-90.

Greimas, A.J. 1987. On Meaning. Minneapolis : University of Minnesota.

Harcup, T. and D. O'Neill. 2001. What Is News? Galtung and Ruge revisited. Journalism Studies 2(2):261-280.

Herkenrath, M. and A. Knoll. 2011. Protest events in international press coverage : An empirical critique of cross-national conflict databases. International Journal of Comparative Sociology 53(3) :163-180.

Lévêque, S. and D. Ruellan (eds). 2010. Journalistes engagés. Rennes : Presses Universitaires de Rennes.

Hamilton, J.M. and E. Jenner. 2004. Redefining Foreign Correspondence. Journalism 5(3) :301-321.

Marty, E., Rebillard, F. and N. Smyrnaios. 2009. Online News between Redundancy and Diversity : A Quantitative Study of French Speaking News Websites. Colloque new media and communication. Athens, 6-9 may.

Östgaard, E. 1965. Factors Influencing the Flow of News. Journal of Peace Research 2(1) :39- 63.

Patterson, T.E. 2000. Doing well and doing good. Kennedy School of Government Working Paper, 01-001.

Peterson, S. 1981. International news selection by the elite press : A case study. Public Opinion Quarterly 45(2) :143-163. 
Rastier, F. 2011. La mesure et le grain : sémantique de corpus. Paris : Champion.

Rosengren, K.E. 1970. International news : intra and extra media data. Acta Sociologica 13(2) : 96-109.

Sarkar, M.B., Butler, B. and C. Steinfield. 1995. Intermediaries and Cybermediaries : a continuing role for mediating players in the electronic marketplace. Journal of Computer-Mediated Communication 1(3) :1-14.

Sande, Ø. 1971. The perception of foreign news. Journal of Peace Research $8(3 / 4): 221-237$.

Schramm, W. 1949. The Nature of News. Journalism Quarterly 26(3) :259269.

Schulz, W.F. 1982. News structure and people's awareness of political events. Gazette 30 : 139-153.

Severo, M., L. Beauguitte and H. Pecout. 2015. Archiving news on the Web through RSS flows. A new tool for media studies. RESAW Proceedings, June, Aarhus.

Staab, J.F. 1990. The role of news factors in news selection : A theoretical reconsideration. European Journal of communication 5(4), 423-443.

Stoll, M.A. 2005. Geographical skills mismatch, job search and race. Urban Studies 42(4) :695- 717.

Thussu, D.K. 2007. News as Entertainment : The Rise of Global Infotainment. London : Sage.

Tuchman, G.1973. Making News by Doing Work : Routinizing the Unexpected. American Journal of Sociology 79(1):110-131.

Veron, E., Dana, J. and De Ferrière, A.F. 1981. Construire l'événement : les médias et l'accident de Three Mile Island. Paris : Les Éditions de Minuit.

Wu, D.H. 2000. Systemic Determinants of International News Coverage : A Comparison of 38 Countries. Journal of Communication 50(2) :110-130.

Zinna, A. 2004. Le interfacce degli oggetti di scrittura : teoria del linguaggio e ipertesti. Rome : Meltemi Editore srl. 